\title{
A Prática como Componente Curricular da Licenciatura em Matemática: Sugestões de Professores da Educação Básica
}

\author{
Practice as Curricular Component Degree in Mathematical Education of \\ Teachers of Basic Tips
}

\author{
Luciane Cristina Sarro \\ lucsarro@gmail.com
}

Roseli Pacheco Schnetzler

rpschnet@unimep.br

\begin{abstract}
Resumo
Esta pesquisa de mestrado se propôs a identificar as sugestões que 14 professores de Matemática da Educação Básica conferem à Prática como Componente Curricular (PCC) em cursos de Licenciatura em Matemática, considerando suas experiências acadêmicas e profissionais. Os dados desta pesquisa foram construídos a partir de entrevistas semiestruturadas realizadas junto àqueles professores, as quais foram gravadas e transcritas. Por meio da análise de conteúdo de tais transcrições foi possível organizar as informações em duas grandes categorias temáticas: experiências acadêmicas de professores de Matemática da Educação Básica e experiências profissionais de professores de Matemática da Educação Básica, considerando desafios que enfrentam no dia a dia de trabalho e alternativas para superá-los. Tais categorias, por sua vez, justificam as sugestões por eles apontadas para a Prática como Componente Curricular de cursos de Licenciatura em Matemática.
\end{abstract}

Palavras-chave: Licenciatura em Matemática. Prática como componente curricular. Formação docente inicial.

\begin{abstract}
This thesis of master's degree propose to identify the suggestions of 14 basic education mathematics teachers give to the practice as part of the curricular component for a mathematics undergraduation courses considering their academics and professional experiences. The data of this research were created from semi structured interview been done with the teachers, which were recorded and transcribed. Through the analyses of its content was possible to organize the information acquired in to two main thematic categories: academics experiences of basic education mathematics teachers and professional experiences from basic education mathematics teachers, considering challenges faced day to day and the alternative to overcome them. These categories justify their suggestions for the practice as a curricular component for the mathematics undergraduation courses.
\end{abstract}

Keywords: Mathematics undergraduation. Practice as a curricular component. Initial training.

\section{Introdução}

Após a implantação da LDBEN de 1996 e seus diversos pareceres, entre os quais se destaca o Parecer CNE/CP $n^{\circ}$ 9/2001, que determina as Diretrizes Curriculares Nacionais para a Formação de Professores da Educação Básica, em nível superior, curso de Licenciatura, de graduação plena, com a intenção de melhorar a prática na formação de professores. Além 
disso, foi publicado na Resolução CNE/CP n 2, de 19 de fevereiro de 2002, que as 400 horas de PCC devem ser distribuídas nos projetos pedagógicos e serem vivenciadas ao longo do curso, garantindo a articulação entre a teoria e a prática, formando, assim, o professor para a docência.

Entretanto, as análises das legislações e as pesquisas realizadas pelos educadores matemáticos, como Nacarato e Passos (2007), Castro e Fiorentini (2008), Gama (2009), Gatti e Nunes (2009), Gatti (2010), Marcatto e Penteado (2013), bem como as análises realizadas pela Sociedade Brasileira de Educação Matemática (SBEM), apontam que as resoluções não deixam claro como deve acontecer a inclusão das 400 horas de PCC nos cursos de Licenciatura, mas apenas determinam que façam parte dos projetos pedagógicos, o que tem gerado dúvidas entre os coordenadores de cursos e os licenciandos que foram entrevistados.

Diante do exposto, a questão de investigação desta investigação é a seguinte: quais são as sugestões de professores de Matemática da Educação básica para as Práticas como Componentes Curriculares (PCC) nos cursos de Licenciatura em Matemática?

Atualmente, entre as pesquisas realizadas na formação docente inicial, muitas delas enfocam o estágio supervisionado como componente curricular, pois ele poderia auxiliar os futuros professores na atuação da carreira docente, sendo por meio dele que os licenciandos entram em contato com a sala de aula. Apesar de os estudos afirmarem sua importância, o estágio sozinho não é suficiente para solucionar os problemas que surgem na escola.

Nesse sentido, a importância do estágio como componente curricular na formação inicial foi confirmada entre as várias pesquisas feitas no estudo da arte realizado, em 2013, sobre o tema, em que foram analisados 15 trabalhos entre dissertações e teses, investigado pela educadora Matemática Marisol Vieira de Melo, com o título “As práticas de formação no estágio curricular supervisionado na Licenciatura em Matemática: o que revelam as pesquisas acadêmicas brasileiras na década 2001-2010”. Segundo a autora, o estágio como componente curricular

pode ser favorável para a produção de conhecimentos dos futuros professores, tanto na escola em parceria com os professores escolares quanto na Universidade com os formadores e seus pares, por intermédio das diferentes práticas (MELO, 2013, p. 339).

De acordo com esse entendimento, todas as disciplinas que formam o currículo precisam ter essa preocupação, principalmente no que se refere a como ensinar determinados conteúdos no Ensino Fundamental e Médio. Dessa forma, o ingresso para muitos licenciados poderia ser 
mais fácil, pois alguns encontram dificuldades ao enfrentar os problemas cotidianos da sala de aula e muitos desistem da profissão.

Para Melo (2013), a realização do estágio como componente curricular não é uma parceria tão fácil de realizar, não depende apenas das políticas públicas, mas que ele seja integrado com a formação inicial. Reforça ser necessário que durante a Licenciatura ocorra "o desenvolvimento da prática profissional do futuro professor, associando o que o mesmo aprende na Licenciatura com o seu próprio campo de atuação, no contexto escolar" (p. 343). A autora ainda afirma que muitos desistem da profissão "por conta do estágio e do enfrentamento da complexidade escolar e da profissão, onde se revelam conflitos e contradições da prática profissional” (MELO, 2013, p. 343).

O estudo da arte realizado por Gama (2009) apresenta indícios da necessidade de os cursos de formação inicial proporcionarem um maior contato com a escola básica desde o seu início, para amenizar o "choque de realidade" no ingresso à carreira docente. Todavia, conforme afirma Gama (2009, p. 108): "Mesmo vivenciando atualmente um momento de transição nos cursos de formação de professores, os primeiros contatos e experiências com a profissão na formação inicial ainda continuam restritos às disciplinas de prática de ensino e/ou estágio supervisionado".

Nesse sentido, Castro e Fiorentini (2008) alertam que é por meio da experiência em sala de aula que os professores reconhecem a complexidade da prática pedagógica. Segundo esses autores, isso ficou claro na fala de Allan, um licenciando que, ao entrar em contato com a escola no período do estágio, afirma que o aprendizado adquirido na Licenciatura formou-o como um profissional operacional, pois o curso não o ensinou a explorar as ideias, os conceitos matemáticos, tão essenciais para desenvolver as situações problemáticas da prática pedagógica. Assim, na fala de Allan, a "Licenciatura é um bacharelado disfarçado ou perdido em seus objetivos" (CASTRO; FIORENTINI, 2008, p. 137).

Portanto, entendemos que se faz necessário investigar sobre as PCC, pois, conforme as diretrizes (LDBEN/1996 e seus pareceres), elas são mais abrangentes que a prática de ensino e o estágio supervisionado. Essas práticas devem ser distribuídas ao longo do curso e auxiliar o professor para a docência. 


\section{O que aponta a literatura brasileira e internacional sobre a formação docente}

A literatura brasileira e internacional aponta que o professor precisa ser considerado ator no processo educacional, isto é, necessita ter voz e ser ouvido, no sentido de contribuir com as discussões sobre a temática, e junto com seus pares lutar por políticas públicas eficazes voltadas à formação de professores e por melhores condições de trabalho em nosso país. Nacarato (2006, p. 137), em seu estudo, deixa claro que o professor precisa ser ouvido:

O professor vem sendo considerado um produtor de saberes e um ator do processo educacional que precisa ser ouvido e deve participar dos projetos que lhe dizem respeito, quer no âmbito das políticas públicas, quer no âmbito do contexto escolar. O professor passa a ser visto como protagonista do processo educativo.

Nessa perspectiva, esta pesquisa pode ser relevante ao desejar contribuir com a temática sobre a formação docente em Matemática, dando "voz" aos professores de Matemática da Educação Básica a respeito das PCC e, ainda, colaborar no sentido de que sejam repensadas as atuais políticas públicas de nosso país, pois, de acordo com os pesquisadores em educação Matemática, as diretrizes que regulamentam as Licenciaturas dessa área do conhecimento não atendem à formação docente, deixando lacunas.

O modelo de formação adotado nas Licenciaturas, desde sua gênese, recebe o nome de racionalidade técnica, no qual o professor é visto como um técnico, ou seja, um especialista que aplica com rigor, em sua prática cotidiana, as regras que derivam dos conhecimentos científico e pedagógico. São eles que fornecem as bases para a sua ação prática (DINIZPEREIRA, 1999).

Historicamente, a formação do professor de Matemática no Brasil não é diferente, uma vez que o modelo da racionalidade técnica predomina na maioria dos cursos de Licenciatura nesta década, marcado na tradição instrumentalizadora e na técnica. Isso ficou visível nas pesquisas realizadas por Gatti e Nunes (2009), Nacarato e Passos (2007), Marcatto e Penteado (2013) e Santos (2012), os quais investigam as Licenciaturas em Matemática.

Donald A. Schön $(1997,2000)$ é, sem dúvida, um dos autores que têm maior peso na difusão do conceito de reflexão, crítico do modelo formativo da racionalidade técnica, uma vez que, conforme citado, a formação é teórica e separada da prática. Portanto, segundo o autor, não atende às diferentes situações complexas e incertas que as atividades práticas revelam, ao aplicar as técnicas e instruções que a pesquisa científica, com base na ciência, apresenta como solução para os problemas da prática, como se fosse possível resolver todos os casos e alcançar igualmente os alunos com as mesmas técnicas.

Nessa perspectiva, entendemos que a racionalidade técnica reforça a formação de um profissional que segue rotinas em suas práticas, não pensa em seu trabalho, apenas faz o que é 
mandado, aplica soluções lógicas pensadas por outros profissionais para resolver as situações problemáticas mediante teorias e técnicas de ensino que são transferidas e ensinadas a ele. Essa conduta não permite que os professores reflitam sobre suas ações e, assim, remetem a prática a uma mera aplicação instrumental.

Zeichner (1997), entre outros autores, faz críticas a Schön (1983), pois, este não leva em conta o contexto estrutural, político e cultural que precisa estar presente na formação de professores; ademais, a reflexão é individual, voltada para dentro da aula, situação em que os professores sentem-se angustiados. $\mathrm{O}$ autor argumenta que a melhoria do practicum, isto é, dos momentos estruturados da prática pedagógica (estágio, aula prática, tirocínio) na formação de professores, tem necessariamente de levar em conta os aspectos externos que estão influenciando a aula, portanto esses contextos precisam ser articulados na formação de professores. Além de incluir o apoio de colegas no practicum, também é necessário que os professores estejam em contato com as escolas onde irão lecionar.

$\mathrm{O}$ autor ainda defende que os obstáculos à aprendizagem do professor que podem impedir a melhoria do practicum relacionam-se com as mudanças na experiência deste em três níveis: organizacional, curricular e estrutural. Porém, não se trata de experiência na profíssão, mas, sim, no processo de formação inicial durante o período do desenvolvimento do practicum. Todavia, as barreiras são:

1. A anterior visão dominante do practicum como uma aprendizagem não mediada e não estruturada, que tem subjacente a ideia de que basta colocar os alunos-mestres junto de 'bons' professores para que se obtenham bons resultados. 2. A ausência de um currículo explícito para o practicum e de uma ligação estreita entre as aprendizagens na Universidade e nas escolas (Turney et al., 1985). 3. A qualidade irregular da supervisão do practicum e a falta de preparação formal, quer dos orientadores universitários, quer dos orientadores das escolas (Stones, 1984). 4. O estatuto inferior dos 'estudos clínicos' nas instituições terciárias, o que resulta com frequência numa exiguidade de recursos para o practicum e num acréscimo de trabalho para os docentes universitários envolvidos na 'formação clínica' de professores (Kerr, 1983; Schneider, 1986; Clifford \& Guthrie, 1988). 5. A importância secundária concedida ao practicum nas escolas primárias e secundárias. Feiman-Nemser e Buchmann (1985) referem os erros que podem ser induzidos pelo fator experiência na formação de professores, bem como o 'perigo da definição de objectivos contraditórios'. Habitualmente, as preocupações dos professores centram-se na aprendizagem dos alunos nas salas de aula, e não no processo de aprender a ensinar (Low, 1988). 6. A discrepância entre o papel do profissional envolvido numa prática reflexiva, que emite julgamentos e toma decisões sobre o currículo e o ensino, e o papel do professor como técnico que excuta de forma eficiente as instruções governamentais e as políticas educativas (ZEICHNER, 1997, p. 119-120).

De acordo com Pérez-Gómez (1997), vários autores convergem em concepções semelhantes do processo prático, definindo-o como prática reflexiva ou aprendizagem baseada na reflexão 
prática para a formação de professores. A partir dessa nova perspectiva e por meio de novos conceitos, haverá possibilidade de "abolir da investigação, da ação e da formação dos profissionais o dilema falso, [...] que ao longo de décadas impediu a comunicação entre investigação, a prática e a formação" (PÉREZ-GÓMEZ, 1997, p.113).

Nesse sentido, compreendemos que se desenvolveu uma nova forma de olhar para a formação docente, pois não basta formar um professor reflexivo de sua prática. A formação é um processo muito mais complexo, uma vez que envolve outros fatores externos que necessitam ser investigados, pesquisados e criticados, não apenas no individual, mas também no coletivo, no intuito de encontrar alternativas para a formação inicial.

Percebemos, diante do exposto nos fóruns já realizados pela SBEM, que nesses últimos anos a preocupação dos educadores matemáticos aumentou em relação ao processo de ensino e aprendizagem da disciplina e à formação docente, o que tem possibilitado o desenvolvimento de pesquisas que procuram sustentar as práticas pedagógicas com base nas investigações e teorias, gerando a consciência nos professores de que precisam trazer para si a necessidade de participar intensamente da criação de políticas públicas sobre a formação docente. Assim, eles podem contribuir com ações educativas mais eficazes nas Licenciaturas.

Após a leitura dos relatórios dos referidos fóruns nacionais e paulistas realizados pela SBEM, identificamos indícios de que tanto as Licenciaturas em Matemática como a PCC ainda necessitam de pesquisas devido à "nebulosidade" que paira sobre elas.

Dessa forma, entendemos que as Licenciaturas, ao inserirem as PCC desde o início do curso, precisam possibilitar aos alunos uma compreensão dos conteúdos matemáticos de maneira clara e conveniente para a vida escolar e fora dela. Isso não se dá apenas com a aplicação de enormes listas de exercícios para serem memorizados e praticados pelos licenciados, mas principalmente quando a prática profissional assumir um papel central no processo de formação.

Assim, é importante que o professor formador (e também o futuro professor)

incorpore a reflexão sobre a sua prática para que seja capaz de tomar decisões fundamentais, relacionando-as a projetos a serem empreendidos, e ao modo como efetivá-los, deixando de ser um simples executor e passando a ser considerado um profissional investigador (SANTOS, 2012, p. 227).

Constatamos que a formação docente carece de mudanças urgentes visando à melhoria na formação inicial. Assim, os pesquisadores têm buscado alternativas nas PCC, uma vez que a legislação vigente determina que elas sejam inseridas desde o início do curso nas 
Licenciaturas, porém não esclarece como fazê-lo. Diante dessa importante questão, resta-nos perguntar: como realizar essa inclusão?

Compreendemos que uma das saídas para melhorar a formação docente foi discutida no percurso desta investigação, ou seja, a formação baseada na nova epistemologia da prática reflexiva crítica, pois ela desconsidera o modelo da racionalidade técnica e leva em conta a atuação dos professores ao enfrentarem os problemas reais na prática pedagógica, partindo dela e em direção a ela retornar num processo contínuo de ação-reflexão-ação e investigação. Dessa forma, o professor, ao refletir sobre a sua própria prática pedagógica, torna-se um investigador e assim (re)produz novos conhecimentos diante da realidade que vivencia no cotidiano do ambiente de trabalho.

Nesse sentido, Schnetzler (2000, p. 25) deixa claro que a formação de professores reflexivos/pesquisadores depende dos formadores

\begin{abstract}
tanto os da vertente curricular específica/científica, nos institutos ou departamento de química, física e biologia, quanto daqueles alocados nas faculdades de educação. Em ambos os contextos, o formador precisa ser capaz de refletir sobre a sua própria prática de formação, investigando-a, num processo contínuo para torná-la mais efetiva.
\end{abstract}

Diante do que se apresenta, entendemos ser essencial que os formadores possuam conhecimentos científicos da sua área de atuação e tenham experiência da prática para a qual estão formando os alunos, para conseguirem auxiliá-los a dialogar de modo reflexivo com as dificuldades da prática pedagógica, de modo que eles possam enfrentá-las, investigando-as para vencer os desafios do seu dia a dia de trabalho.

Realizamos a pesquisa na abordagem qualitativa, que foi desenvolvida com base em entrevistas semiestruturadas conduzidas pela pesquisadora. Os 14 sujeitos entrevistados estavam lecionando Matemática na Educação Básica na rede pública de ensino no ano letivo de 2013. Por meio da análise temática, identificamos sugestões de tais professores em relação ao nosso objeto de pesquisa, ou seja, à PCC.

Para tanto, dividimos essa análise em duas grandes categorias temáticas: experiências acadêmicas de professores de Matemática da Educação Básica, com foco nas opiniões desses docentes a respeito do curso de Licenciatura que fizeram, e engloba as seguintes subcategorias: aspectos positivos e negativos do curso; disciplinas que colaboraram e disciplinas que não colaboraram para a atuação do professor em sala de aula e experiências profissionais de professores de Matemática da Educação Básica, considerando desafios que 
enfrentam no cotidiano de trabalho, e aborda as seguintes subcategorias: desafios que os professores enfrentam para ensinar os conteúdos matemáticos no dia a dia de trabalho; busca de alternativas pelos professores para poderem superar tais desafios.

Ambas as categorias, por sua vez, justificam as sugestões apresentadas pelos professores para a PCC em cursos de Licenciatura em Matemática. Buscamos fazer nessa análise interpretativa a articulação entre o objetivo do estudo, a base teórica estudada e o material produzido nas entrevistas com os referidos docentes.

É necessário, primeiramente, relembrar que a opção em entrevistar os professores de Matemática da Educação Básica para contribuir com o debate sobre a temática, consiste no fato de não se encontrar estudos que deem voz a esses docentes, no que diz respeito às PCC nas Licenciaturas em Matemática, e ainda por se tratar de um assunto pouco explorado na literatura brasileira.

Os estudos que analisamos da literatura brasileira que envolvem as 400 horas de PCC na Licenciatura em Matemática investigam projetos pedagógicos de Licenciaturas e entrevistam coordenadores de cursos, professores formadores e licenciandos, conforme os trabalhos desenvolvidos pelos educadores Nacarato e Passos (2007), Castro e Fiorentini (2008), Manrique e Perentelli (2008), Rocha e Fiorentini (2009), Nogueira e Pereira (2012), Nogueira (2012), Hoepers e Fernandes (2012), Marcatto (2012), Marcatto e Penteado (2013) e Figueiredo e Lobo da Costa (2013a, 2013b, 2013c).

Esses estudos evidenciam que as leis que regem a formação inicial, em especial as 400 horas de PCC, determinam a inclusão dessas horas desde o início do curso, formando, assim, o professor para a docência, mas não esclarecem como fazê-lo. Isso foi comprovado pelos autores ao entrevistarem os coordenadores e professores formadores, os quais declaram que essa questão tem gerado dúvidas no momento de montar os projetos pedagógicos das Licenciaturas. E, ainda, os licenciandos entrevistados afirmam que da maneira como essas práticas vêm sendo realizadas na formação inicial não estão auxiliando-os para atuarem nas escolas de Educação Básica.

\section{Com a palavra os Professores de Matemática da Educação Básica}

Dos 14 professores de Matemática da Educação Básica entrevistados, 11 cursaram o curso de Licenciatura em Matemática. Somente dois (2) dos professores consideram o curso de licenciatura em Matemática, como ótimo e bom, e a maioria nove (9) afirma que o curso 
deixou a desejar e, entre os pontos negativos, foi citado que faltou abordar como ensinar os conteúdos matemáticos na Educação Básica. Assim, o curso não os formou para a sala de aula, pois foi voltado para o bacharelado e, ainda, que o curso não cumpriu o seu papel, pois precisaria formar os docentes para trabalhar com crianças, jovens e adultos. As principais deficiências apontadas por eles residem no fato de as IES, além de não formarem docentes para ensinar os conteúdos matemáticos, não ensinam também como lidar com os estudantes, pois estes são pessoas com diferentes histórias de vida e possuem necessidades formativas diversificadas. Por isso, alguns dos professores participantes da pesquisa revelam que, quando iniciaram a profissão docente, sentiram o "choque de realidade" e relatam a continuação dessa deficiência, uma vez que, os professores recém-formados também chegam à escola com dificuldades de ensinar os conteúdos matemáticos escolares. Soma-se a isso a dificuldade que estes professores têm em lidar com alunos indisciplinados. Assim, muitos deles desistem da profissão e vão procurar outro emprego.

Chamou-nos a atenção nas falas dos professores que o curso não ensinou como ensinar os conteúdos da Educação Básica; por esse motivo, não se sentiram formados para atuar em sala de aula. Para as autoras Schnetzler (2000), Silva e Schnetzler (2006) e Santos (2012), essa deficiência poderia ser amenizada se os professores das Licenciaturas praticassem a reelaboração conceitual com os licenciandos, pois os conteúdos científicos ensinados necessitam ser transformados pedagogicamente em conteúdos de ensino.

Quanto a aspectos positivos, duas professoras relatam que o curso tinha ótimos professores e que se preocupavam com as dificuldades dos alunos. $O$ fato de estarem lecionando proporcionava experiências que podiam compartilhar com seus colegas e professores durante o período da Licenciatura.

Com referência ao curso de Licenciatura, ao refletirmos sobre as disciplinas que colaboram e as que não colaboram na formação do professor, segundo os depoentes, fica evidente que são aquelas de conteúdos matemáticos voltados para o ensino na Educação Básica que contribuem, como Matemática I, II, III e IV, e também as disciplinas de Estágio, embora estas tenham recebido duras críticas devido à maneira como são realizadas nas escolas da Educação Básica.

A literatura analisada na investigação aponta que isso pode acontecer porque os professores formadores das Licenciaturas, que lecionam as disciplinas específicas do curso, geralmente são matemáticos e, assim, lecionam uma Matemática científica, e não ensinam aos licenciandos a transformar pedagogicamente esses conteúdos científicos em conteúdos escolares, segundo processos de reelaborações conceituais. 
Pensando na melhoria da formação inicial, buscamos focar as sugestões dos professores da Educação Básica para trabalhar com as 400 horas de PCC, na tentativa de minimizar essas deficiências no período da formação inicial, e, assim, diminuir também a tensão na inserção dos futuros professores em sua profissão.

Ao analisarmos os depoimentos dos docentes desta pesquisa em relação à importância da inclusão dessas horas, inferimos que, para eles, a sala de aula é o melhor lugar para o futuro professor aprender a ser professor. Dessa forma, as práticas necessitam começar desde o início do curso e na escola básica. Assim, os licenciandos teriam a oportunidade de praticar na escola o que estão aprendendo, na teoria, nas IES. A interação de professores com alunos da Educação Básica e o auxílio dos docentes formadores proporcionariam condições para os licenciandos discutirem sobre os conteúdos que irão ensinar na Educação Básica.

No entanto, os professores entrevistados apontam que essas horas precisam ser aplicadas de forma diferente do modelo como os estágios foram e vêm sendo desenvolvidos na maioria das escolas, uma vez que estes acontecem, geralmente, sem a supervisão dos professores da universidade e da escola: o estagiário fica sentado no fundo da sala de aula, sem participar, sem dar aulas, sem discutir sobre os conteúdos matemáticos com os professores da escola e com os professores universitários. Esse modelo praticado até agora na maioria das escolas invalida a importância da prática, servindo apenas para cumprir as burocracias da formação.

Outro aspecto marcante nesse contexto revelado pelos entrevistados é que, se o futuro professor não estiver dentro da escola no período de formação, não tiver experiência em sala de aula como professor, não conhecer a realidade da escola e dos alunos, acabará desistindo da profissão. Portanto, é necessário que essas práticas sejam desenvolvidas em escolas, públicas e privadas, em diferentes regiões da cidade e nos níveis de Ensino Fundamental e Médio, pois cada escola é diferente e cada aluno é único; logo, nesse caso não cabem receitas prontas elaboradas por aqueles que não estão no dia a dia da sala de aula e nem no contexto escolar.

\section{Considerações finais}

Enfim, entendemos que as colocações e sugestões que os professores de Matemática da Educação Básica fazem para tais práticas no período de formação na Licenciatura assemelham-se às alternativas que a literatura estudada revela. Diante desse contexto, compreendemos que as políticas públicas brasileiras necessitam ser revistas, a fim de que sejam mais esclarecedoras, principalmente no que diz respeito à inclusão das 400 horas de PCC. 
Acreditamos que a investigação possa contribuir para o debate acerca da temática, ao reafirmar, segundo a visão dos professores da Educação Básica, a importância dessas práticas na formação inicial e trazer sugestões para que elas sejam mais bem organizadas na Licenciatura e praticadas desde o início do curso em escolas de Educação Básica, com a devida supervisão dos professores da universidade e dos professores experientes da escola. A pesquisa poderá contribuir, também, ao reafirmar que, durante a formação inicial, os professores formadores incluam, nessas horas de prática, reelaborações conceituais de conteúdos matemáticos, com vistas a um processo de ensino-aprendizagem mais significativo para a Educação Básica.

\section{Referências}

CASTRO, Franciana Carneiro; FIORENTINI, Dario. Tornando-se professor de matemática: o caso de Allan em prática de ensino e estágio supervisionado. In: FIORENTINI, Dario (Org.). Formação de professores de matemática: explorando novos caminhos com outros olhares. Campinas: Mercado de Letras, 2008. p. 121-156.

DINIZ-PEREIRA, J. E. As licenciaturas e as novas políticas educacionais para a formação docente. Educação \& Sociedade. Campinas, ano XX, n. 68, p. 109-125, dez. 1999. Disponível em: <http://www.scielo.br/pdf/es/v20n68/a06v2068.pdf>. Acesso em: 2 abr. 2013.

GAMA, Renata Prenstteter. Professores iniciantes e o desenvolvimento profissional: um olhar sobre as pesquisas acadêmicas brasileiras. In: FIORENTINI, Dario; GRANDO, Regina Célia; MISKULIN, Rosana Giaretta Sguerra (Org.). Práticas de formação e de pesquisa de professores que ensinam matemática. Campinas: Mercado de Letras, 2009. p. 101-123. (Série Educação Matemática).

GATTI, B. A. Formação de professores no Brasil: características e problemas. Educação \& Sociedade, Campinas, v. 31, n. 113, p. 1355-1379, out./dez. 2010. Disponível em: $<$ http://www.scielo.br/pdf/es/v31n113/16.pdf > . Acesso em: 10 set. 2012.

GATTI, B. A.; NUNES, M. M. R. (Org.). Formação de professores para o ensino fundamental: estudo de currículos das licenciaturas em pedagogia, língua portuguesa, matemática e ciências biológicas. São Paulo: FCC/DPE, 2009. (Coleção Textos FCC, v. 29).

MARCATTO, F. S. F.; PENTEADO, M. G. O lugar da prática nos projetos pedagógicos de licenciatura em matemática. Acta Scientiae, Canoas, v. 15, n. 1, p. 61-75, jan./abr. 2013. Disponível em: <http://www.periodicos.ulbra.br/index.php/acta/article/ view/345/361>. Acesso em: 20 set. 2013.

MELO, Marisol Vieira. As práticas de formação no estágio curricular supervisionado na licenciatura em matemática: o que revelam as pesquisas acadêmicas brasileiras na década 2001-2010. 2013. Tese (Doutorado em Educação)-Universidade Estadual de Campinas, Campinas, 2013. 
NACARATO, A. M. A formação do professor de matemática: pesquisa x políticas públicas. Contextos e Educação, ano XXI, n. 75, p. 131-152, jan./jun. 2006. Disponível em: $<$ https://www.revistas.unijui.edu.br/index.php/contextoeducacao/article/view/1114/870>.

Acesso em: 4 abr. 2013.

NACARATO, A. M.; PASSOS, C. L. B. As licenciaturas em matemática no estado de São Paulo. Horizontes, v. 25, n. 2, p. 169-179, jul./dez. 2007. Disponível em: <http://webp. usf.edu.br/itatiba/mestrado/educacao/uploadAddress/Horizontes_25_2_04[11066].pdf>.

Acesso em: 27 abr. 2013.

PÉREZ-GÓMEZ, Angel. O pensamento prático do professor: a formação do professor como profissional reflexivo. In: NÓVOA, António (Org.). Os professores e a sua formação. 3. ed. Lisboa: Publicações Dom Quixote, 1997. p. 95-114.

ROCHA, L. P.; FIORENTINI, D. Percepções e reflexões de professores de matemática em início de carreira sobre seu desenvolvimento profissional. In: FIORENTINI, D.; GRANDO, R. C.; MISKULIN, R. G. S. (Org.). Práticas de formação e de pesquisa de professores que ensinam matemática. Campinas: Mercado de Letras, 2009. p. 125-146. (Série Educação Matemática).

SANTOS, F. A. dos. Evasão discente no ensino superior: estudo de caso de um curso de licenciatura em matemática. 2012. 246 f. Tese (Doutorado em Educação)-Universidade Metodista de Piracicaba, Piracicaba, 2012.

SBEM - Sociedade Brasileira de Educação Matemática. Subsídios para a discussão de propostas para os cursos de Licenciatura em Matemática: uma contribuição da Sociedade Brasileira de Educação Matemática. São Paulo: SBEM, 2003. Disponível em: $<$ http://www.academia.edu/4256113/SUBSIDIOS_PARA_A_DISCUSSAO_DE_PROPOST AS_PARA_OS_CURSOS_DE_LICENCIATURA>. Acesso em: 30 mar. 2014.

SCHNETZLER, R. P. O professor de ciências: problemas e tendências de sua formação. In: SCHNETZLER, R. P.; ARAGÃO, R. M. R. de (Org.). Ensino de ciências: fundamentos e abordagens. Campinas: R. Vieira; Piracicaba: CAPES/UNIMEP, 2000. p. 13-41.

SCHÖN, D. A. Educando o profissional reflexivo: um novo design para o ensino e a aprendizagem. Tradução Roberto Cataldo Costa. Porto Alegre: Artes Médicas Sul, 2000.

SILVA, L. H. de A.; SCHNETZLER, R. P. A mediação pedagógica de uma disciplina científica como referência formativa para a docência de futuros professores de Biologia. Ciências \& Educação, v. 12, n. 1, p. 57-72, 2006.

ZEICHNER, Kenneth M. Novos caminhos para o practicum: uma perspectiva para os anos 90. In: NÓVOA, António (Org.). Os professores e sua formação. 3. ed. Lisboa: Publicações Dom Quixote, 1997. p. 118-138. 